\title{
Fluctuations in warfarin dose response after heart valve surgery: implications for cardiac rehabilitation
}

\author{
Fluttuazione della risposta alle dosi di warfarin \\ dopo cardiochirurgia valvolare: implicazioni \\ per la riabilitazione cardiologica
}

\author{
Marco Ambrosetti, Walter Ageno1, Alberto Calori, Sandro Ferrarese2, \\ Annalisa Barosi, Paolo Marchetti, Luciano Salvato, Andrea Sala2
}

\begin{abstract}
Fluctuations in warfarin dose response after heart valve surgery: implications for cardiac rehabilitation. M. Ambrosetti, W. Ageno, A. Calori, S. Ferrarese, A. Barosi, P. Marchetti, L. Salvato, A. Sala.

In patients undergoing heart valve surgery (HVS) who require warfarin therapy, the maintenance of low variability in the level of anticoagulation early after operation is generally difficult. Aim of this study was to evaluate the time in therapeutic range (TTR) in HVS patients receiving oral anticoagulation therapy (OAT) during phase I-II of cardiac rehabilitation (CR), and, secondly, to identify clinical variables associated with inadequate anticoagulation.

Methods: Observational study of consecutive in-hospital patients directly tracked from a cardiac surgery unit to a CR facility. OAT was monitored both in terms of administered warfarin doses and resulted INR values, from day 1 to day 15 after operation. Clinical variables were tested in a logistic regression model for the prediction of inadequate anticoagulation, defined as the presence of nontherapeutic INRs for $\geq \mathbf{5}$ days between day 8 and 15 .

Results: Eighty-one patients (males $56 \%$, age $62 \pm 19$ yrs.), following valvuloplasty $(37 \%)$, mechanical $(17 \%)$, and
\end{abstract}

bioprosthetic ( $45 \%)$ valve replacement were considered. The prescribed warfarin dosages were significantly higher from day 1 to day 7 than from day 8 to day $15(4.6 \pm 3.6$ and 3.0 \pm 1.1 $\mathrm{mg}$ respectively, $\mathrm{p}<0.001$ ). Overall, TTR was $6 \pm 3$ days, while time with elevated and lower INRs accounted for $1.3 \pm 1.6$ and $8.0 \pm 3.5$ days respectively. At day 7 , only $25 \%$ of patients $(n=$ 20) showed a therapeutic INR value. Inadequate anticoagulation between postoperative day 8 and 15 was displayed in $41(51 \%)$ patients, with hypertension as the only independent predictor $(p<0.001)$ at multivariate analysis.

Conclusions: Despite intensive monitoring, half of patients have nontherapeutic INR values (mainly subtherapeutic) in the first two weeks after HVS while on warfarin. Giving the high risk of completing the hospitalization phase without a stable OAT in many patients, both cardiac surgeons and cardiologists should not miss the opportunity to improve patients education, and consider a direct track to anticoagulation management services after discharge.

Keywords: anticoagulation, valve surgery, cardiac rehabilitation.

Monaldi Arch Chest Dis 2009; 72: 29-32.

Cardiovascular Rehabilitation Unit, Le Terrazze Clinic, Cunardo (VA), Italy.

1 Department of Clinical Medicine, University of Insubria, Varese, Italy.

2 Department of Surgical Sciences, Cardiac Surgery Unit, University of Insubria, Varese, Italy.

Corresponding author: Dr. Marco Ambrosetti; Cardiovascular Rehabilitation Unit, Le Terrazze Clinic; Via U. Foscolo, 6/b I-21035 Cunardo (VA), Italy; E-mail address: m.ambrosetti@clinicaleterrazze.com

\section{Introduction}

In patients undergoing heart valve surgery (HVS), the importance of achieving an anticoagulation balance which prevents both adverse thromboembolic and hemorrhagic complications is well recognized. Despite advances in reducing thrombogenicity of newer generation valves and the availability of safer anticoagulation regimens, thromboembolism and anticoagulant-related bleeding still account for up to $75 \%$ of all complications within six months after HVS [1]. In the long-term, poor anticoagulation control with high variability of the international normalized ratio (INR) is the strongest independent predictor of reduced survival [2], and a cumulative increase in the risk of adverse events is generally observed during lifelong treatments for mechanical valves.

In Italy more than 50,000 cardiac interventions are currently performed every year, $40 \%$ of which require valve implantation. Based on the First Database Report [3] of the Italian Society for Cardiac Surgery, mechanical HVS per se might account for over 12,000 per year new initiations of lifelong anticoagulation therapies nationwide. While recommendations for long-term anticoagulation after HVS have been extensively formulated, little evidence exists for the optimal management of anticoagulation in the early postoperative period. As such, a clear comparison of the most common strategies currently adopted (i.e., oral warfarin starting on postoperative day one (i) without the use of heparin; 
(ii) with intravenous unfractionated heparin; (iii) with low molecular weight heparin beginning in the early hours after surgery and continuating until a therapeutic INR has been achieved) is not actually available [1]. With an average postoperative hospitalization of 10 days [3], it could be reasonably argued that HVS patients rarely display optimal and stable levels of anticoagulation at discharge from surgery units, due to haemodynamic and haemostatic alterations induced by cardiopulmonary bypass.

Multidisciplinary cardiac rehabilitation (CR) programmes showed clear benefits after cardiac surgery. To date, patients undergoing HVS account for up to one fourth of all patients referred to CR programs (data from the 2008 Italian SurveY of carDiac rEhabilitation - Scientific Committee of the Italian Society of Cardiac Rehabilitation and Prevention, personal communication), and a growing body of literature was historically devoted to the improvement in functional capacity as a result of exercise training after operation [4]. However, since CR should be a multidimensional intervention also designed to reduce condition-related morbidity and mortality and enhance quality of life, an adequate management of anticoagulation may be identified as a major core component of programs delivered.

Aim of this study was to evaluate the time in therapeutic range (TTR) in patients after HVS receiving oral anticoagulation therapy during phase III of CR, and secondly, to identify clinical variables associated with inadequate anticoagulation.

\section{Methods}

We performed an observational study of consecutive HVS patients directly tracked from a cardiac surgery unit to a CR facility. Oral anticoagulation therapy - as managed by the attending physician, with a starting dose of $5 \mathrm{mg}$ warfarin on postoperative day 1 plus weight-adjusted doses of enoxaparin until a therapeutic INR has been achieved - was monitored both in terms of administered warfarin doses and resulted INR values, from day 1 to day 15 after operation. INR monitoring was performed daily until the therapeutic range had been achieved and maintained for at least 2 consecutive days. Then, the frequency of testing depended on the stability of dose response, and INR variations were derived according to the linear interpolation method with a minimal tolerance of 0.1 . The optimal intensity of oral anticoagulation, with related INR ranges and targets for different operations, was derived from the seventh American College of Chest Physicians Anticoagulation Consensus Guidelines [5], the latest available at the time of the study period. Clinical variables were tested in a logistic regression model for the prediction of inadequate anticoagulation (defined as the presence of nontherapeutic INRs for $\geq 5$ days between day 8 and 15, when an observable anticoagulant effect had been reasonably achieved), if significant differences emerged at univariate analysis. During the study period, a strict survey for thromboembolic (namely, the presence of thrombi in the proximity of valves as identified by echocardiography, or the evidence of peripheral and coronary embolization) and bleeding (namely, documented bleeding requiring transfusion, $>1 \mathrm{~cm}$ thickness pericardial effusion, or central nervous system hemorrhage accidents) complications was instituted.

\section{Results}

Eighty-one patients (males $56 \%$, age $62 \pm 19$ yrs.), following valvuloplasty (38\%), mechanical (17\%), and bioprosthetic (45\%) valve replacement, and with operational site in the mitral $(37 \%)$, aortic $(43 \%)$, and multiple $(20 \%)$ position, were considered.

The prescribed warfarin dosages were significantly higher from day 1 to day 7 than from day 8 to day 15 after operation $(4.6 \pm 3.6$ and $3.0 \pm 1.1 \mathrm{mg}$ respectively, $\mathrm{p}<0.001)$.

The level of anticoagulation in the whole sample from day 1 to day 15 is shown in figure 1. Overall, TTR was $6 \pm 3$ days, while time with elevated and lower INRs accounted for $1.3 \pm 1.6$ and $8.0 \pm 3.5$ days respectively. An INR of $>5.0$ was detected in 5 $(6 \%)$ patients. At day 7 , only $25 \%$ of patients $(n=$ 20) showed a therapeutic INR value. Inadequate anticoagulation between postoperative day 8 and 15 was displayed in $41(51 \%)$ patients, with a significant higher prevalence of the following clinical conditions (figure 2) as compared to those who did not: hypertension ( $49 \%$ vs $12 \%$, p < 0.001 ), hypercholesterolemia $(37 \%$ vs $12 \%, \mathrm{p}<0.05)$, chronic renal impairment ( $37 \%$ vs $0 \%, \mathrm{p}<0.001$ ), and presence of operation in the mitral position $(49 \%$ vs $25 \%$, p < $0.05)$. Demographic characteristics, diabetes, adoption of antiarrhythmic drugs or antibiotics, and biochemistry data (with the exception of elevated liver enzymes) did not show significant differences between the two groups. At multivariate analysis, only hypertension $(\mathrm{p}<0.001)$ predicted the development of inadequate anticoagulation in the short-term after HVS. During the study period, no postoperative complications related to anticoagulation occurred.

\section{Discussion}

In this observational study focused on the early postoperative period after HVS, we found that half of patients had inadequate anticoagulation despite intensive INR monitoring, in absence of major anticoagulation-related events under strict medical supervision.

As mentioned above, an effective anticoagulation strategy should be part of the early management of patients after HVS, aimed to minimize the risk of thromboembolic events and bleeding complications. In patients following mitral valve replacement, the risk of thromboembolic events is up to 21 per 100 patient years in the early postoperative period as compared to 2.5 per 100 patient in the subsequent 5-year follow-up, and a similar trend is shown after aortic valve replacement and valvuloplasty at a less degree of risk [6]. On the other hand, major bleeding events may occurr in up to $3 \%$ of HVS patients immediately after the initiation of oral anticoagulants, with gastrointestinal and intracranial hemorrhages as those associated with the highest morbidity and mortality [7]. As reported by Ageno et al [8,9], patients are highly sensitive to warfarin during the first 5 days of anticoagulation after HVS, and require a great number of dose adjustements. According to our data, the 


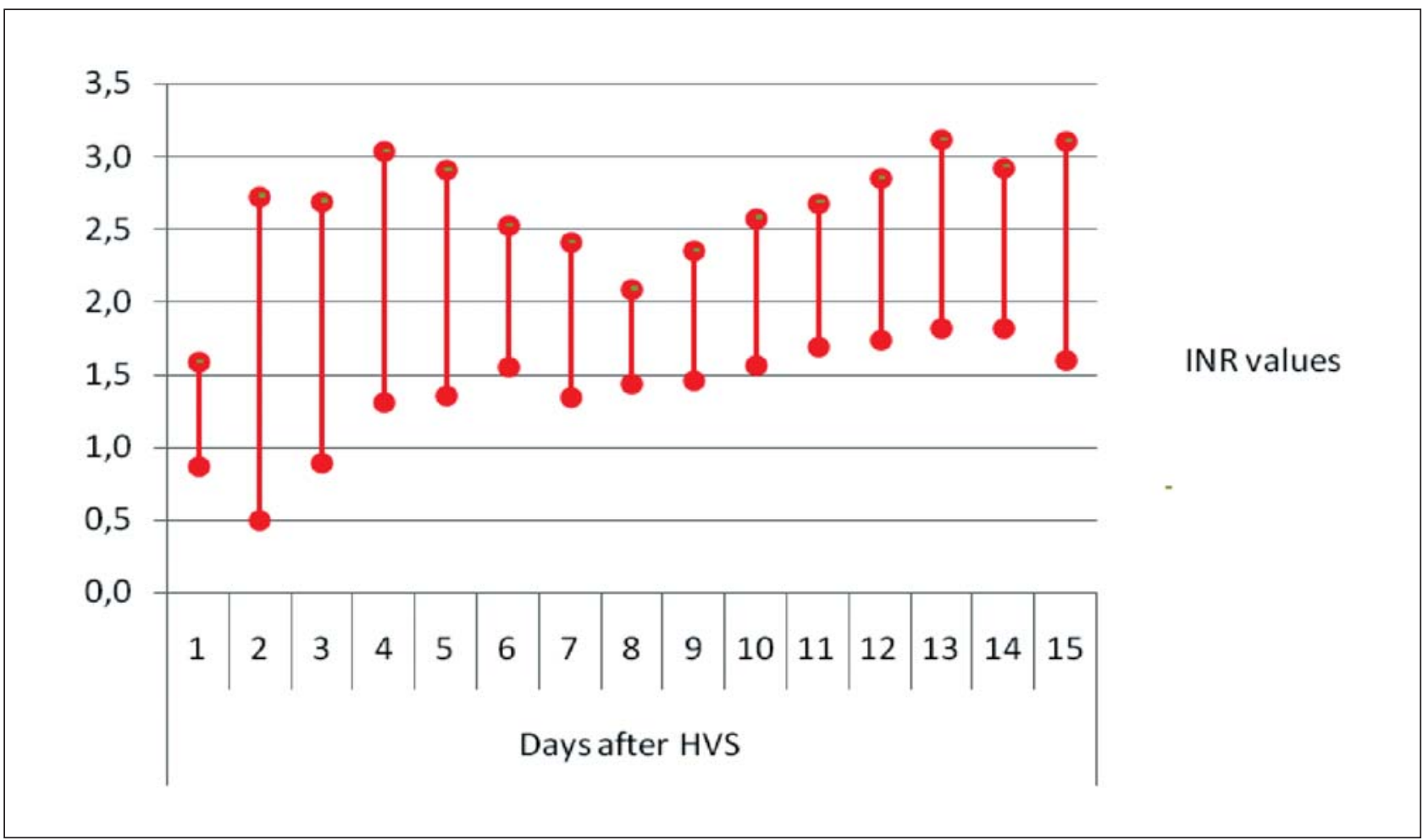

Figure 1. - Levels of anticoagulation (expressed as mean \pm SD INR) from day 1 to day 15 after heart valve surgery (HVS).

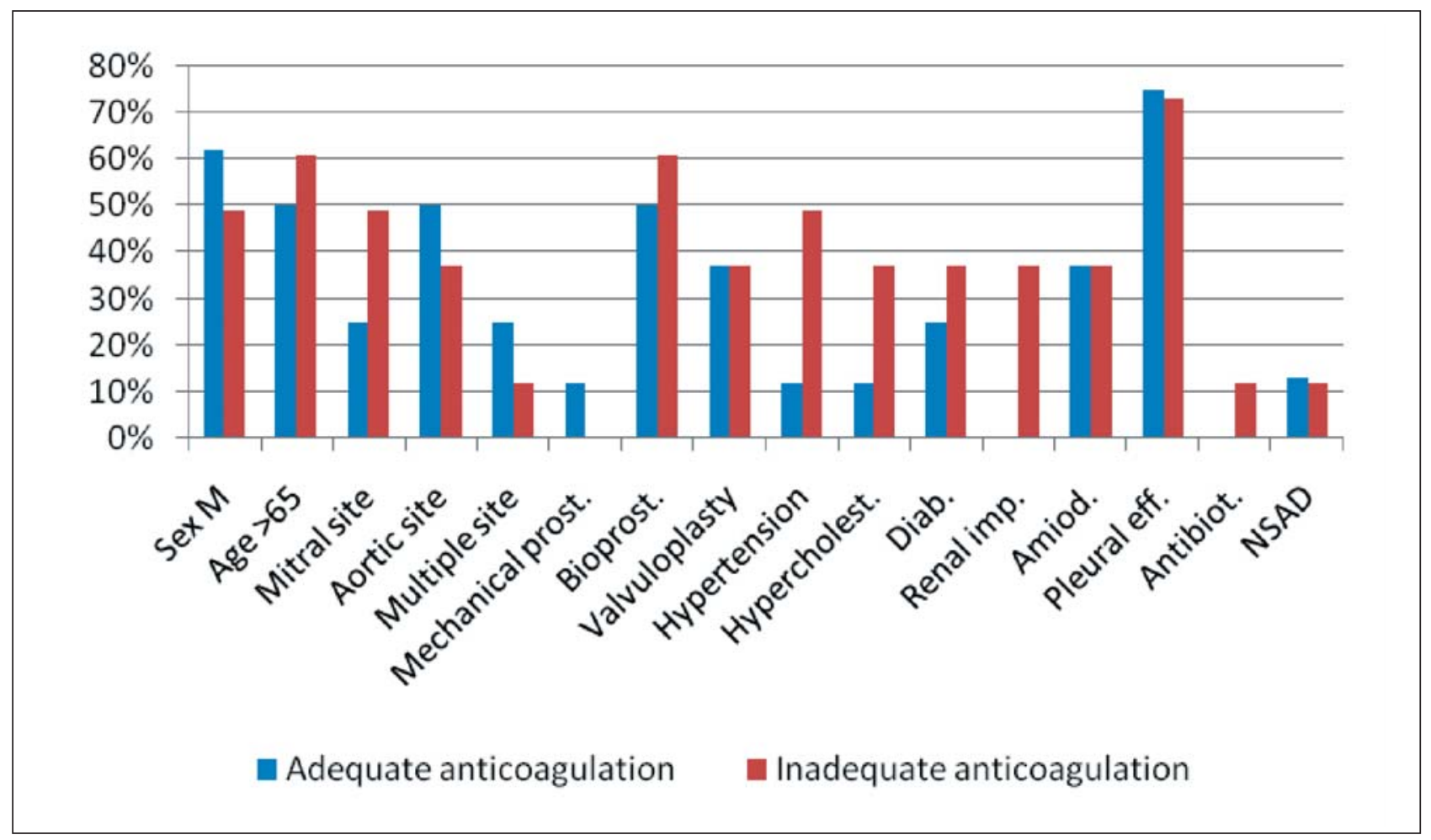

Figure 2. - Presence of different clinical characteristics among patients with adequate and inadequate anticoagulation from day 8 to day 15 after heart valve surgery.

maintenance of a stable dose response is a major concern also during the second week after operation, and the evenience of subtherapeutic rather than exaggerated anticoagulation seems to be predominant.

Unfortunately, several pathogenetic factors related to HVS patients, as far as the lack of a large consensus on the optimal anticoagulation strategy in the early postoperative period, contribute to reduce the proportion of patients who receive the proven level of effective care. Facing the development of prosthetic or native valve thromboembolism (in case of valve replacement or repair respectively), is a challenge that begins immediately after surgery: once the cardiopulmonary bypass terminates and blood flows across the valves, platelets start to aggregate and adhere on damaged perivalvular tissues 
and prosthetic surface, while the activation of coagulation factors promotes clot formation. In the following period, other patient-related factors may further enhance thrombogenicity, as in case of delayed endothelization of exposed surfaces, or blood stasis induced by postoperative atrial fibrillation, dilated cardiac chambers, and regional wall motion abnormalities. To preserve the integrity of valves with the lowest rate of bleeding, most work has been related on the optimal intensity of oral anticoagulation in the long-term, defined as the target INR on which different HVS interventions should be anticoagulated. Less attention was conversely paid to the correct strategy for rapidly achieving these INR targets, comprehensive of the disadvantages that often emerge in the early postoperative setting, such as the increased risk of hemopericardium and mediastinic bleeding, the persistence of haemostatic imbalance, the presence of infections, and the use of antibiotic or antiarrhytmics drugs that interfere with oral anticoagulants. Indeed, an integrated approach to the issue of anticoagulation management after HVS should also consider other aspects affecting the decision-making process, such as the role of non-traditional risk factors for valve thromboembolism (i.e., smoking, hypertension, and cancer history), the different degree of thromboembolic risk according to the anatomic valve position (leading to more or less aggressive antithrombotic strategies), and the concomitant use of antipletelet drugs.

In this perspective, it's not surprising that anticoagulation - rather than other postoperative care interventions - often needs to be supervised and refined over the first two weeks after HVS, thereby claiming a patient oriented process. According to the mission of CR in HVS patients, a coordinated intervention on the matter of anticoagulation cannot be limited to manage warfarin doses, but should also include a baseline clinical assessment of the individual thromboembolic and haemorrhagic risk, the correction of conditions potentially interfering with a stable anticoagulation, and the provision of structured patient education. Giving the high risk of completing the rehabilitative phase without a stable dose response in many patients, a direct track to anticoagulation management services after discharge could be promoted as part of follow-up plans.

\section{Riassunto}

Il mantenimento di uno stabile livello di efficace scoagulazione nei pazienti sottoposti a cardiochirurgia valvolare, seppure di grande importanza, è generalmente difficile nelle prime fasi dopo l'intervento. Scopo del presente lavoro è stato valutare il tempo intercorso in range terapeutico di scoagulazione in una popolazione di pazienti sottoposta a valvuloplastica o sostituzione valvolare e direttamente afferenti a una struttura di cardiologia riabilitativa.
In questo studio osservazionale una popolazione di 81 pazienti è stata valutata in termini di dosi di warfarin prescritte e valori di INR raggiunti nel periodo intercorrente tra il $1^{\circ}$ e il $15^{\circ}$ giorno postoperatorio, inserendo in un modello di analisi multivariata le comuni variabili cliniche potenzialmente predittrici di inadeguata scoagulazione (quest'ultima definita come la presenza di un INR non terapeutico per $\geq 5$ giorni tra la giornata 8 e 15, allorquando uno stabile livello di scoagulazione dovrebbe essere concretamente raggiunto).

Risultati: Nei pazienti considerati $37 \%$ in esiti di valvuloplastica, $17 \%$ di sostituzione valvolare meccanica e $45 \%$ di sostituzione valvolare con protesi biologica), i dosaggi prescritti di warfarin sono stati significativamente maggiori nella prima rispetto alla seconda settimana di osservazione $(4.6 \pm 3.6$ e $3.0 \pm 1.1 \mathrm{mg}$ rispettivamente, $p<0.001)$. Globalmente, il TTR è stato di $6 \pm 3$ giorni, con $1.3 \pm 1.6 e$ $8.0 \pm 3.5$ giornate caratterizzate da eccessivamente alti e bassi livelli di INR, rispettivamente. Una scoagulazione inadeguata durante la seconda settimana è stata riscontrata globalmente in 41 (51\%) pazien$t i$, con la sola ipertensione arteriosa a costituire un parametro predittivo indipendente di tale condizione.

Conclusioni: Nonostante un monitoraggio intensivo dell'INR, circa metà dei pazienti dopo cardiochirurgia valvolare presentano valori di INR decisamente instabili nelle prime due settimane dopo l'intervento, generando un rischio clinico di complicanze tromboemboliche ed emorragiche da non sottovalutare, soprattutto nel setting della riabilitazione cardiologica.

\section{References}

1. Kulik A, Rubens FD, Wells PS, et al. Early postoperative anticoagulation after mechanical valve replacement: a systematic review. Ann Thorac Surg 2006; 81(2): 770-781.

2. Butchart EG, Payne N, Li HH, et al. Better anticoagulation control improves survival after valve replacement. $J$ Thorac Cardiovasc Surg 2002; 123: 715-723.

3. First Database Report of The Italian Society for Cardiac Surgery, update 2003. www.sicch.it

4. Williams MA, Ades PA, Hamm LF, et al. Clinical evidence for a health benefit from cardiac rehabilitation: an update. Am Heart J 2006; 152: 835-841.

5. Salem DN, Stein PD, Al-Ahmed A et al. Antithrombotic therapy in valvular heart disease - native and prosthetic: the seventh ACCP conference on antithrombotic and thrombolytic therapy. Chest 2004; 126: 4575-4825.

6. Heras M, Chesebro JH, Fuster V, et al. High risk of thromboemboli early after bioprosthetic cardiac valve replacement. J Am Coll Cardiol 1995; 25: 1111-1119.

7. Sakorafas GH, Tsiotos GG. Intra-abdominal complications after cardiac surgery. Eur J Surg 1999; 165: 820-827.

8. Ageno W, Turpie AG. Exaggerated initial response to warfarin following heart valve replacement. Am J Cardiol 1999; 84(8): 905-908.

9. Ageno W, Turpie AG, Steidl L, et al. Comparison of a daily fixed $2.5-\mathrm{mg}$ warfarin dose with a 5-mg, international normalized ratio adjusted, warfarin dose initially following heart valve replacement. Am J Cardiol 2001; 88(1): 40-44. 